\title{
Risk management in carbon capture and geological storage: insights from a structured expert elicitation
}

\section{Patricia Larkin*}

McLaughlin Centre for Population Health Risk Assessment, University of Ottawa,

Room 216A, 600 Peter Morand Crescent, Ottawa, K1G 5Z3, Ontario Canada

Email: plarkin@xplornet.com

*Corresponding author

\section{Robert Gracie}

Department of Civil and Environmental Engineering, University of Waterloo,

200 University Avenue West, Room E2-2321,

Waterloo, N2L 3G1, Ontario, Canada

Email: rgracie@uwaterloo.ca

\section{Ali Shafiei}

Department of Petroleum Engineering, School of Mining and Geosciences, Nazarbayev University,

53 Kabanbay Batyr Ave., Nur-Sultan, 010000, Republic of Kazakhstan

Email: ali.shafiei@nu.edu.kz

\section{Maurice Dusseault}

Department of Earth and Environmental Sciences, University of Waterloo,

200 University Avenue West, EIT-2043, Waterloo, Ontario, N2L 3G1, Canada

Email: mauriced@uwaterloo.ca

\section{Mirhamed Sarkarfarshi}

CIBC Global Markets,

Toronto, Ontario Canada

Email: Sarkarfarshi@gmail.com 


\title{
Willy Aspinall
}

School of Earth Sciences,

University of Bristol,

Beacon House, Queens Road, Bristol, BS8 1QU, UK

Email: willy.aspinall@bristol.ac.uk

\section{Daniel Krewski}

McLaughlin Centre for Population Health Risk Assessment, University of Ottawa,

Room 216A, 600 Peter Morand Crescent,

Ottawa, Ontario K1G 5Z3, Canada

Email: dkrewski@uottawa.ca

\begin{abstract}
With a focus on risk management (RM) in injection and storage for carbon capture and geological sequestration (CCS), an expert elicitation of scientific judgements quantified collective uncertainty ranges for a number of difficult environmental and human health risk challenges. Results suggest similarities and differences in opinions, an outcome that may be reflective of both the newness and the complexity of this technology. A suitable monitoring period was estimated at about a century; however, uncertainty was three orders of magnitude, with an upper (5th percentile) value of almost 1,000 years. For selected low probability high impact georisks, only site selection and monitoring were considered 'very' effective RM options. Monitoring, well integrity studies, emergency response plan, automatic emergency shut down system and training were considered 'very' or 'extremely' effective in managing two risks more directly related to human health. Experts responded with a wide uncertainty spread for a regulated threshold of minor, major and catastrophic leakage. A companion paper discusses elicitation findings for issues related to risk assessment.
\end{abstract}

Keywords: carbon capture and storage; expert elicitation; risk management; injection; sequestration; health environment.

Reference to this paper should be made as follows: Larkin, P., Gracie, R., Shafiei, A., Dusseault, M., Sarkarfarshi, M., Aspinall, W. and Krewski, D. (2019) 'Risk management in carbon capture and geological storage: insights from a structured expert elicitation', Int. J. Risk Assessment and Management, Vol. 22, Nos. 3/4, pp.404-428.

Biographical notes: Patricia Larkin is a Post-Doctoral Fellow at the University of Ottawa. Her field of research, population health, considers structural and intermediary determinants of health and their interactions, with a goal to protect or improve human health. With a focus on applied risk management, she is undertaking research, writing and project management at the McLaughlin Centre for Population Health Risk Assessment and the Institute for Science Society and Policy. She is an active member of the Society for Risk Analysis. She holds her Master in Geography and Graduate Diploma in Population Health Risk Assessment and Management. 
Robert Gracie is an Associate Professor at the Department of Civil and Environmental Engineering, at the University of Waterloo (UW). His PhD from Northwestern University focused on the Simulation of Deformation and Fracture of Solids in 2009, prior to which he analysed interactions between ice, soil and offshore pipelines at Natural Resources Canada. At UW, he teaches courses in solid mechanics, finite element analysis and nonlinear computational mechanics and carries out research in the development of numerical methods to simulate the deformation and fracture of solids and the flow of fluids. He is known for his work on the extended finite element method (XFEM), which was developed specifically to simulate fracture, dislocations and multiphase flow. $\mathrm{He}$ has 27 journal articles on related topics. His current research projects include developing new simulation technologies for multiphase-phase flow during carbon sequestration, hydraulic fracturing of rock masses and microscale plasticity.

Ali Shafiei is an Assistant Professor of Petroleum Engineering with the Department of Petroleum Engineering at Nazarbayev University (NU) in Kazakhstan. He is a founding team member of the petroleum engineering program in NU and leads the BSc program in Petroleum Engineering. $\mathrm{He}$ completed his $\mathrm{PhD}$ in 2013 in Heavy Oil Recovery and Reservoir Geomechanics from the University of Waterloo in Canada. At NU, he teaches petrophysics, well logging, formation evaluation, petroleum geology, reservoir geomechanics, and heavy oil recovery. His current research projects include low salinity water flooding and asphaltene precipitation in petroleum reservoirs. As of today, his professional and academic experience has resulted in more than 40 refereed journal papers, vetted conference proceedings, chapters in books and monographs. He is an active member of the SPE, EAGE, and AAPG. He is also a Faculty Advisor of the NU SPE Student Chapter.

Maurice Dusseault teaches geological engineering and does research in deep underground engineering issues including hydraulic fracturing, energy storage, geothermal energy, mining, carbon sequestration, deep solids and liquids waste disposal through injection and wellbore integrity. He holds over 80 international patents and has about 525 full-text papers published in journals and conferences. He is a well-known educator and advisor and in the last few years has served as advisor to five different Canadian provinces (AB, QC, NB, $\mathrm{NS}$, and NL) on matters relating to energy development, hydraulic fracturing, energy geostorage, wellbore integrity, technology and innovation.

Mirhamed (Araz) Sarkarfarshi completed his PhD at the Department of Civil and Environmental Engineering, University of Waterloo. He currently works as a Senior Quantitative Analyst, Capital Markets Risk Management, CIBC Toronto, Ontario, Canada.

Willy Aspinall is a consulting Chartered Scientist and Chartered Geologist and Cabot Professor in Natural Hazards and Risk Science at the University of Bristol, UK. His main interests are in risk assessment, volcanology and seismology and the formalised use of expert judgement in decision-making for low probability, high consequence events in circumstances of scientific uncertainty. He specialises in facilitating expert elicitations in medical, climate, Earth science and other science-based fields. He was awarded the 2012 William Smith Medal of the Geological Society of London for excellence in contributions to applied geoscience and was co-recipient with Bristol University colleagues of the 2014 Lloyd's of London Science of Risk Prize for Natural Hazards and the 2015 The Queen's Anniversary Prize for Higher and Further Education. 
Daniel Krewski is a Professor of Epidemiology and Community Medicine at the University of Ottawa, where he also serves as Scientific Director of the McLaughlin Centre for Population Health Risk Assessment. His research interests include epidemiology, biostatistics, health risk assessment and risk management. He is a Fellow of the Society for Risk Analysis, the American Statistical Association and a national affiliate of the US National Academy of Sciences. He holds the Natural Sciences and Engineering Research Council of Canada Chair in Risk Science at the University of Ottawa.

\section{Introduction}

Carbon capture and geological storage (CCS) has been identified as a mitigation option for climate change. This technological process can reduce carbon dioxide $\left(\mathrm{CO}_{2}\right)$ emissions at point source fossil fuel and industrial process sites such as coal and natural gas electricity generation facilities, or cement, steel, fertiliser and oil upgrader facilities (IEA, 2009, 2013; IPCC, 2005, 2014). In 2010, $\mathrm{CO}_{2}$ from fossil fuel and industrial processes was estimated at $31.85 \mathrm{GtCO}_{2} \mathrm{e} /$ year, accounting for $65 \%$ of total annual anthropogenic GHG emissions, up from 55\% in 1970 (IPCC, 2014). Electricity and heat production and direct industry emissions accounted for a further $12.25 \mathrm{GtCO}_{2} \mathrm{e} /$ year and $10 \mathrm{GtCO}_{2} \mathrm{e} /$ year ( $25 \%$ and $21 \%$ of GHG emissions, respectively) (IPCC, 2014).

The overarching purpose of CCS is long term retention of $\mathrm{CO}_{2}$ in deep geological formations, where large scale integrated projects (LSIPs) have the capacity to store at least 800,000 tonnes of $\mathrm{CO}_{2}$ annually for a coal-based power plant or at least 400,000 tonnes of $\mathrm{CO}_{2}$ annually for other emissions from intensive industrial facilities (including natural gas-based power generation) (GCCSI, 2016). Estimates suggest that up to 3,000 dedicated large scale geological sequestration storage projects, storing a cumulative $123 \mathrm{GtCO}_{2}$, are necessary worldwide if CCS is to achieve a projected $13 \%$ reduction in $\mathrm{CO}_{2}$ emissions by 2050 and thus making a measurable contribution to climate change mitigation (GCCSI, 2014; IEA, 2013).

CCS projects include four value chain activities: $\mathrm{CO}_{2}$ capture and compression to a supercritical state, pipeline transport, deep wellbore injection and permanent storage in geological formations (i.e., saline aquifers). While addressing the global environmental and human health impacts of climate change, the overarching goal for CCS project proponents and regulators is to ensure local safety and environmental protection while storing $\mathrm{CO}_{2}$ for the long term. Indeed, environmental and human health hazards have been identified for each of the value chain activities. When CCS projects were first initiated, risk assessment and management of capture and transport chain activities were better known and understood than injection and storage components (Damen et al., 2006; Koornneef et al., 2012). Today, research and experience are improving understanding and reducing uncertainty in the latter activities (Pawar et al., 2014, 2015).

With a focus on injection and storage in saline aquifer sequestration projects, an expert elicitation of scientific judgements was convened in an effort to quantify collective uncertainty judgements for a number of complex environmental and human health risk challenges related to CCS. The present paper provides findings related to risk management, including options for addressing low probability high impact events. The 
elicitation also considered issues in risk assessment, findings for which are detailed in a companion article (Larkin et al., 2019a).

\subsection{Structured expert elicitation}

Structured expert elicitation has been shown to be of value where there is limited experience and large uncertainties, but where risks are considered very low (Aspinall, 2010). CCS, in particular sequestration in saline aquifers, is a relatively new technology that falls within these parameters.

Since the early 1990s, structured expert elicitation has been used to discern risk ranking, uncertainty and risk management options for wide ranging issues of societal importance (Cooke and Goossens, 2008; Oraby et al., 2016; Tyshenko et al., 2012, 2011). With respect to CCS, this approach has been recommended within a suite of tools to be used in risk assessment (Gerstenberger et al., 2013). It was also applied in a research project, in combination with Bayesian Belief Networks analysis, in considering the detection and stabilisation of a potential $\mathrm{CO}_{2}$ plume in the $\mathrm{CO}_{2} \mathrm{CRC}$ Otway Stage $2 \mathrm{C}$ experiment (Australia) (Gerstenberger and Christophersen, 2016).

\subsection{Elicitation parameters}

The portion of the facilitated expert elicitation reported here focuses on environmental and human health risk management issues for saline aquifer sequestration projects, particularly with respect to injection and storage and management of low probability high impact (LPHI) events. Carbon capture utilisation and storage (CCUS) projects are also operational, particularly for enhanced oil recovery (EOR) operations that use $\mathrm{CO}_{2}$ in a miscible flood. Another CCUS project type is enhanced coal bed methane (CBM) recovery operations, where injected $\mathrm{CO}_{2}$ remains permanently stored in the coal. $\mathrm{CBM}$ are the least common CCUS projects undertaken to date (MIT, 2018).

Environmental and human health issues associated with CCS have been discussed in broad terms by Wilson et al. (2003) and included both local environmental risks $\left(\mathrm{CO}_{2}\right.$ in the atmosphere or shallow subsurface; $\mathrm{CO}_{2}$ dissolved in subsurface fluids; and geological displacement) and the risk to the global environment, should project leaks re-emit stored $\mathrm{CO}_{2}$ to the atmosphere. More recently Koornneef et al. (2012), Bowden et al. (2013b) and Pawar et al. (2015) expanded the spectrum of environmental risks for the natural environment: $\mathrm{CO}_{2}$, brine or process contaminants can affect air, soil and groundwater quality. Bowden et al. (2013a), in their list of biosphere risks, extended this further to include wildlife, prairie, recreation and industry assets related to air, soil and water issues. Jones et al. (2015) reviewed research and experience regarding the potential impacts of $\mathrm{CO}_{2}$ leakage on potable water resources and ecosystems.

Project level human health hazards include exposure to supercritical $\mathrm{CO}_{2}$ and the effects of induced seismicity on built infrastructure (Koornneef et al., 2012). Morbidity and mortality can result from inhalation of elevated $\mathrm{CO}_{2}$ concentrations in the atmosphere, should there be a sudden release of the supercritical $\mathrm{CO}_{2}$ stream. Seismicity could affect human populations should the built infrastructure become weakened. Furthermore, re-release of $\mathrm{CO}_{2}$ could worsen GHG concentrations in the atmosphere, thereby contributing to climate change, with concomitant environmental and health risks. This is also germane from a population health perspective, as environmental conditions are an important determinant of health. 


\section{Methods}

The elicitation methods are described in detail in the companion article that provides findings with respect to important issues in risk assessment (Larkin et al., 2019a).

In brief, twelve international experts participated in the structured expert elicitation using video conferencing over two consecutive part-days in March 2015. Five participants from government research centres and seven from academia had extensive expertise in varied aspects of geoscience, risk assessment and monitoring. The group first arrived at a common understanding of terms and context, with an emphasis that the elicitation did not concern a specific project site but that the location of a project would be away from major urban centres. Other understandings included leakage types and failure scenarios and the boundary between injection and storage activities. Additional questions of clarification and group interpretation were permitted throughout the process. Experts completed and returned elicitation target questions individually within distributed spreadsheet file response tables. Partial results for one participant, who withdrew voluntarily from the elicitation after the first day, are not included in the analysis.

The risk management target questions had two formats:

1 Numerical uncertainty distribution. In preparation for numerical uncertainty distribution target questions, the elicitation began with expert calibration under Cooke's Classical Model (Cooke, 1991). This step provided a distinct performance weight (PW) for each expert statistically based on their ability to judge uncertainties, as established by their accuracy (best judgement) and uncertainty informativeness ( $90 \%$ credible range) for eighteen questions for which the answers were known. The Cooke Classical Model is the only currently available technique that enables genuine empirical control such that the result of the PW median solution and associated uncertainty distribution is a valid representation of the group view (Aspinall and Cooke, 2013; Cooke, 1991, 2013).

Experts then answered target questions with best judgement responses for the quantity in question (50th percentile), as well as the 90\% credible range (lower limit 5th percentile and upper limit 95th percentile). Risk management questions considered the regulated threshold for likelihood of storage leakage, safe storage lifetimes, long term retention, storage monitoring period and relative effort and project costs that should be focused on risk management.

Calibration and target question responses in this format were processed using the EXCALIBUR software package (Cooke, 1991; Cooke and Goossens, 2008; Tyshenko et al., 2011).

2 Likert scale rating. A 5-level Likert scale was used to elicit expert opinion on the effectiveness of six risk management (RM) options for five low probability high impact (LPHI) events. A description for each level of effectiveness was provided: not at all effective (1); minimally effective (2); moderately effective (3); very effective (4); extremely effective (5). Prior to providing their responses, the experts added an additional level: (6) '0/not applicable'.

The rated LPHI events were: large migration out of pore space, caprock fracture, induced seismic event $\mathrm{M}>4$, massive release of $\mathrm{CO}_{2}$ resulting in human fatalities and catastrophic wellhead injection failure. The RM options were: site selection, well 
integrity studies, emergency response plans, monitoring, automatic emergency shut down system and training (operating procedures).

Expert panel responses in this section were also converted to equivalent pairwise preference matrix form and re-processed with the Unibalance Probabilistic Inversion algorithm (Macutkiewicz and Cooke, 2006).

Likert scale responses and associated paired comparisons were not weighted based on calibration question responses used in the numerical uncertainty distribution format. However, pairwise preferences were checked for internal consistency.

Following completion of the structured elicitation, a third facilitated video conference session provided experts with preliminary findings. Some of these findings, combined with expert comments, suggested further clarification of some items would be beneficial. An explanatory document summarising the rationale for such clarifications was distributed electronically and all experts completed and submitted responses to the re-elicitation target questions on an individual basis.

\section{Results}

\section{$3.1 \quad$ Numerical uncertainty distributions}

Table 1 provides the median performance-weighted responses and $90 \%$ credible intervals provided by the experts for risk management target questions. The supplementary material [online] includes figures with individual expert responses, performance weight (PW) and equal weight (EW) distributions, along with composite plots of comparative piece-wise uncertainty distributions for linked target items, representing the three quantiles (i.e., 5th, 50th and 95th percentiles) of aggregated performance weighted judgements. Figures 1 and 2 provide examples of these representations. Re-elicited questions include $\mathrm{R}$ suffix in numbering.

a regulated threshold for likelihood of minor, major or catastrophic storage leakage

TQ37R-39R - preamble:

Large scale integrated projects (LSIPs) have capacity for at least 800,000 tonnes of $\mathrm{CO}_{2}$ annually for a coal-based power plant, or at least 400,000 tonnes of $\mathrm{CO}_{2}$ annually for other emissions-intensive industrial facilities (including natural gas-based power generation) (GCCSI, 2014).

What should be the regulated threshold for the likelihood of minor, major or catastrophic storage leakage in a LSIP sequestration project ( 1 in $X$, where $X \geq 1$; for example, 1 in 100 would represent a $1 \%$ likelihood)?

Having agreed to an understanding of three CCS leakage failure scenarios, Table 1 indicates a decreasing median regulated threshold moving from minor, to major, to catastrophic scenarios, as well as wide solution uncertainty spread for all three scenarios. However, there is some separation into high and low risk 'schools of thought' in all three cases (supplementary material). It appears there are significant differences of opinion within the expert panel, perhaps indicating that this risk management option has not been previously considered thoroughly or in detail by the participants. 
Table 1 Median performance-weighted responses and $90 \%$ credible intervals provided by the experts to target questions

\begin{tabular}{|c|c|c|}
\hline Target question (unit of response) & $\begin{array}{l}\text { Median } \\
\text { value }\end{array}$ & $\begin{array}{l}90 \% \text { credible } \\
\text { interval }\end{array}$ \\
\hline \multicolumn{3}{|l|}{$\begin{array}{l}\text { TQ37R-39R. What should be the regulated threshold for the } \\
\text { likelihood of minor, major or catastrophic storage leakage in } \\
\text { a LSIP sequestration project ( } 1 \text { in } X \text {, where } X \geq 1 \text {; for } \\
\text { example, } 1 \text { in } 100 \text { would represent a } 1 \% \text { likelihood)? }\end{array}$} \\
\hline Minor leakage & 1 in 202 & $\begin{array}{l}1 \text { in } 39,600 \text { to } 1 \\
\text { in } 2.7\end{array}$ \\
\hline Major leakage & 1 in 4,060 & $\begin{array}{l}1 \text { in } 337,000 \text { to } 1 \\
\text { in } 40\end{array}$ \\
\hline Catastrophic leakage & $\begin{array}{c}1 \text { in } \\
399,000\end{array}$ & $\begin{array}{l}1 \text { in } 1.1 \text { million to } \\
1 \text { in } 338\end{array}$ \\
\hline $\begin{array}{l}T Q 43 R \text { : how long will a typical saline aquifer storage site } \\
\text { remain safe, where safe means } 95 \% \text { or more facilities will not } \\
\text { fail in the time periods you specify (years)? }\end{array}$ & $\begin{array}{l}12,700 \\
\text { years }\end{array}$ & $\begin{array}{l}8.6 \text { million yrs to } \\
166 \text { years }\end{array}$ \\
\hline $\begin{array}{l}T Q 44 R \text { : how long will a typical saline aquifer storage site } \\
\text { remain safe, where safe means } 50 \% \text { or more facilities will not } \\
\text { fail in the time periods you specify (years)? }\end{array}$ & $\begin{array}{l}125,000 \\
\text { years }\end{array}$ & $\begin{array}{l}80 \text { million yrs to } \\
5,130 \text { years }\end{array}$ \\
\hline $\begin{array}{l}T Q 45 R \text { : how long will a typical saline aquifer storage site } \\
\text { remain safe, where safe means } 5 \% \text { or fewer facilities will not } \\
\text { fail in the time periods you specify (years)? }\end{array}$ & $\begin{array}{l}1 \text { million } \\
\text { years }\end{array}$ & $\begin{array}{c}780 \text { million yrs to } \\
15,100 \text { years }\end{array}$ \\
\hline $\begin{array}{l}T Q 46 \text { : in a typical large scale integrated saline aquifer storage } \\
\text { project, what fraction of injected } \mathrm{CO}_{2} \text { can be expected to be } \\
\text { retained over a period of } 1,000 \text { years? }(0-100 \%)\end{array}$ & $99.8 \%$ & $87 \%$ to $100 \%$ \\
\hline $\begin{array}{l}T Q 47 \text { : in a typical large scale integrated enhanced oil } \\
\text { recovery storage project, what fraction of injected } \mathrm{CO}_{2} \text { can be } \\
\text { expected to be retained over a period of } 1,000 \text { years? }(0- \\
100 \%)\end{array}$ & $99.85 \%$ & $54 \%$ to $100 \%$ \\
\hline $\begin{array}{l}T Q 55 \text { : What should be the storage project monitoring period } \\
\text { (years)? }\end{array}$ & 92 years & 8 yrs to 990 years \\
\hline $\begin{array}{l}\text { TQ56: considering potential negative impacts of CCS on } \\
\text { either the environment or human health, what proportion of } \\
\text { risk management should be focused on mitigating } \\
\text { environmental impacts as opposed to human health impacts } \\
(0-100 \%) \text { ? }\end{array}$ & $12 \%$ & $1.1 \%$ to $69 \%$ \\
\hline $\begin{array}{l}T Q 57 \text { : on a project basis, what proportion of costs should be } \\
\text { mandated by the leading regulatory agency to be spent on } \\
\text { environmental and human health protection }(\%) \text { ? }\end{array}$ & $5.5 \%$ & $1.1 \%$ to $17 \%$ \\
\hline $\begin{array}{l}\text { TQ58: assume there is an annual budget for the proponent to } \\
\text { fund operational costs of a CCS storage facility. What } \\
\text { percentage of this budget should be allocated to safety to } \\
\text { ensure sufficient mitigation of environmental and human } \\
\text { health impacts such that the company is reasonably secure } \\
\text { against gross negligence claims in any post-failure litigation } \\
(\%) \text { ? }\end{array}$ & $11 \%$ & $1.1 \%$ to $25 \%$ \\
\hline
\end{tabular}

Notes: $\mathrm{R}$ in question number denotes re-elicitation ${ }^{1}$; ${ }^{1}$ exact meaning should not be ascribed to the precision of these reported results - they should be regarded as indicative. 
b safe storage lifetimes at 'low-end', 'median' and 'high-end' safe storage periods

$T Q 43 R-45 R$ - preamble:

Large scale integrated projects (LSIPs) have capacity for at least 800,000 tonnes of $\mathrm{CO}_{2}$ annually for a coal-based power plant, or at least 400,000 tonnes of $\mathrm{CO}_{2}$ annually for other emissions-intensive industrial facilities (including natural gas-based power generation) (GCCSI, 2014).

Assuming no fundamental change in technology, what is the safe storage lifetime of a typical saline aquifer storage site at the following confidence levels? Please give three durations to express your uncertainty.

$T Q 43 R$ : how long will a typical saline aquifer storage site remain safe, where safe means $95 \%$ or more facilities will not fail in the time periods you specify (years)?

$T Q 44 R$ : how long will a typical saline aquifer storage site remain safe, where safe means $50 \%$ or more facilities will not fail in the time periods you specify (years)?

$T Q 45 R$ : how long will a typical saline aquifer storage site remain safe, where safe means $5 \%$ or fewer facilities will not fail in the time periods you specify (years)?

The experts' median period for facilities remaining safe is 12,700 years, 125,000 years and 1 million years ( $95 \%$ or more; $50 \%$ or more; and $5 \%$ or fewer facilities, respectively) (TQ43-45R, Table 1). Experts' judgement median values showed less uncertainty than EW solutions (supplementary material). One expert indicated lifetimes one-to-two orders longer than other panel members, an individual judgement that extended the uncertainty in all cases (supplementary material).

c long-term retention of $\mathrm{CO}_{2}$

$T Q 46:$ in a typical large scale integrated saline aquifer storage project, what fraction of injected $\mathrm{CO}_{2}$ can be expected to be retained over a period of 1,000 years? $(0 \%-100 \%)$.

$T Q 47$ : in a typical large scale integrated enhanced oil recovery storage project, what fraction of injected $\mathrm{CO}_{2}$ can be expected to be retained over a period of 1,000 years? $(0 \%-100 \%)$.

The most widely-quoted long-term retention target for storage of carbon dioxide is $99 \%$ of injected $\mathrm{CO}_{2}$ remaining underground for 1,000 years (IPCC, 2005). In this question, experts understood retention to be within the identified storage formation immediately adjacent to the injection wells.

The group median estimate judgement is essentially the same for both saline aquifer sequestration and EOR operations, with approximately $99.83 \%$ and $99.85 \%$ of injected $\mathrm{CO}_{2}$ expected to be retained. The uncertainty band is wider for EOR than for saline (TQ46-47, Table 1).

d storage monitoring

TQ55: what should be the storage project monitoring period (years)?

Next to site selection, $\mathrm{CO}_{2}$ monitoring to test for containment and conformance in $\mathrm{CCS}$ projects is the primary risk management activity, where an iterative process to 
calibrate and update risk assessments and monitoring plans is included in many regulatory-based risk management frameworks and non-regulatory guidance documents (Larkin et al., 2019b, 2019c). Jenkins et al. (2015) provide a review of the progress in monitoring and verification in the ten years since the IPCC Special Report on Carbon Capture and Storage (IPCC, 2005).

Experts' uncertainty judgement suggests a coherent view, with median estimate 92 years monitoring activity, i.e., about a century (TQ55, Table 1; Figure 1).

Figure 1 Individual expert responses, performance weight (PW) and equal weight (EW) distributions (see online version for colours)

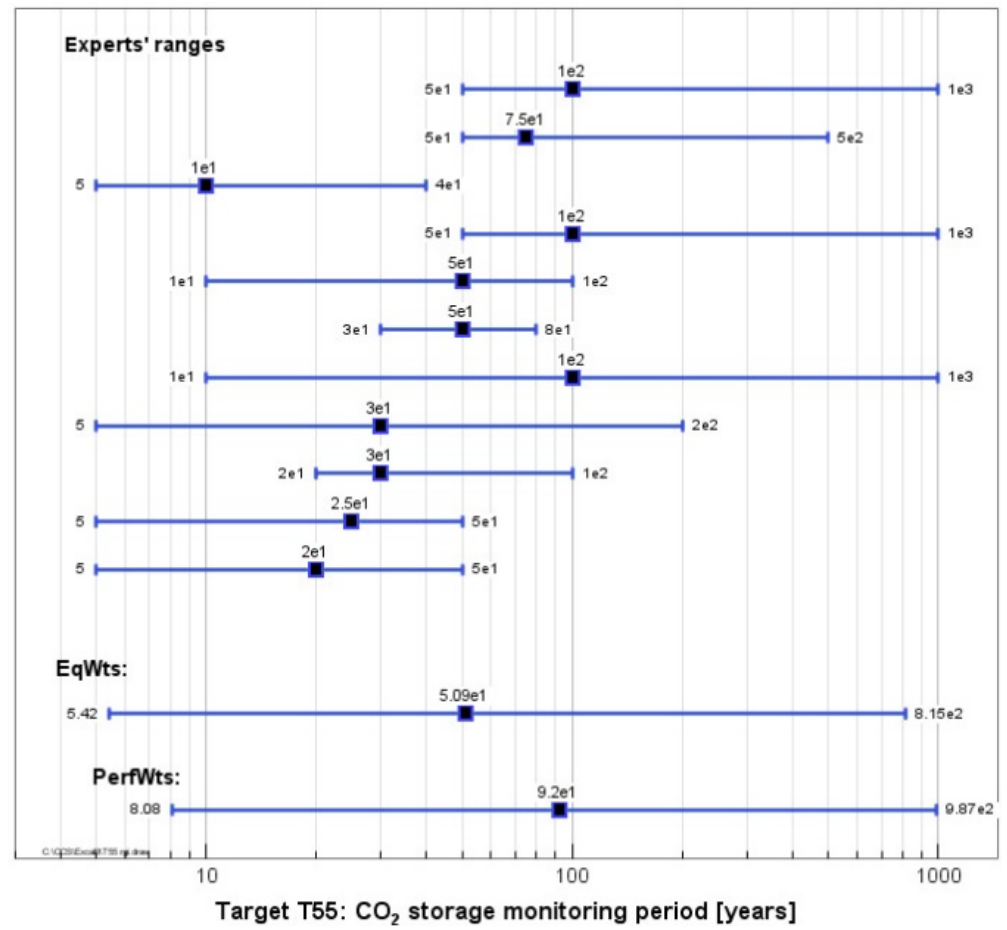

Note: TQ55: what should be the storage project monitoring period (years)?

e a triplet of questions considered the proportion of environment and human health risk management and costs within CCS project operations. Experts limited the estimate to injection and storage implementation, thereby excluding exploration, construction, capture and transport activities.

TQ56: considering potential negative impacts of CCS on either the environment or human health, what proportion of risk management should be focused on mitigating environmental impacts as opposed to human health impacts $(0 \%-100 \%)$ ? 
TQ57: on a project basis, what proportion of costs should be mandated by the leading regulatory agency to be spent on environmental and human health protection (\%)?

$T Q 58$ : assume there is an annual budget for the proponent to fund operational costs of a CCS storage facility. What percentage of this budget should be allocated to safety to ensure sufficient mitigation of environmental and human health impacts such that the company is reasonably secure against gross negligence claims in any post-failure litigation (\%)?

Findings indicate uncertainty distribution of approximately $1 \%-70 \%$ of RM that should be focused on the environment as opposed to human health impacts, with a median estimate of approximately 12\% (TQ56, Table 1).

Experts' median estimate is that approximately $5.5 \%$ of project costs should be mandated by regulatory agencies to protect the environment and human health. This can be compared with experts' response on the percentage budget that should be allocated to safety to ensure sufficient mitigation of environmental and human health impacts, such that the company is reasonably secure against gross negligence claims in any post-failure litigation. Here, the median estimate is approximately $11 \%$ or double the regulated amount (TQ57-58, Table 1; Figure 2).

Figure 2 Composite plot for of comparative piece-wise uncertainty distributions for linked target items, representing the three quantiles (i.e., 5th, 50th and 95th percentiles) of aggregated performance weighted judgements (see online version for colours)

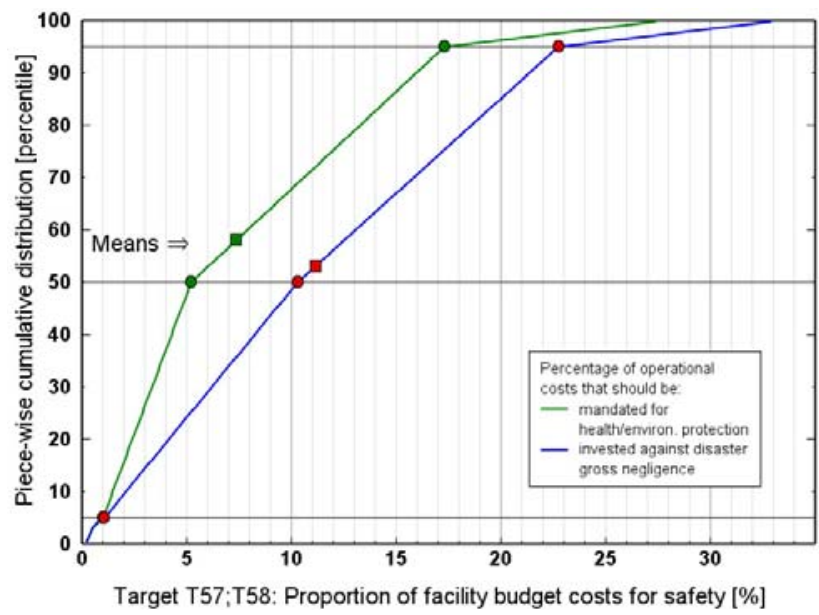

Notes: TQ57: on a project basis, what proportion of costs should be mandated by the leading regulatory agency to be spent on environmental and human health protection (\%)?; TQ58: assume there is an annual budget for the proponent to fund operational costs of a CCS storage facility. What percentage of this budget should be allocated to safety to ensure sufficient mitigation of environmental and human health impacts such that the company is reasonably secure against gross negligence claims in any post-failure litigation (\%)? 


\subsection{Likert scale effectiveness ratings of risk management options}

RM2: This question is focused on risk management of high impact low probability (catastrophic) events. For questions related to leakage, please note that the nature of the leaked substance (e.g., $\mathrm{CO}_{2}$, brine, or another contaminant) is not the focus of the question; rather, the question focuses on a leakage of any kind.

Please rate the effectiveness of each of the following methods to manage risk of high impact low probability (HILP) (catastrophic) events using the following 5-point Likert scale: not at all effective (1); minimally effective (2); moderately effective (3); very effective (4); extremely effective (5); not applicable (6).

Experts rated the effectiveness of site selection, well integrity studies, emergency response plan (ERP), automatic emergency shut down system and training (operating procedures) in managing the five low probability but high impact events discussed below. Prior to their response, experts arrived at an understanding that 'large migration' includes all scenarios such as through a wellbore or geological fault.

Findings are displayed in a heat matrix of mean ratings (Figure 3). With the exception of site selection, all risk management options were considered 'very' or 'extremely' effective in managing risk of potential massive release of $\mathrm{CO}_{2}$ and catastrophic wellhead failure. Only site selection and monitoring were considered 'very' effective risk management options for georisks, namely large migration out of pore space, caprock fracture and induced seismic events $>$ M4. Monitoring was considered moderately or very effective for all LPHI events.

Figure 3 Mean effectiveness rating of six risk management options for five low probability high impact events (see online version for colours)

\begin{tabular}{|l|l|l|l|l|l|l|}
\hline \multicolumn{5}{|c|}{ CCS Risk Management Options } \\
\hline RM Measure & Site Selection & $\begin{array}{c}\text { Well Integrity } \\
\text { Studies }\end{array}$ & $\begin{array}{c}\text { Emergency } \\
\text { Response Plan }\end{array}$ & Monitoring & $\begin{array}{c}\text { Automatic } \\
\text { Emergency Shut } \\
\text { Down System }\end{array}$ & $\begin{array}{c}\text { Training } \\
\text { (operating } \\
\text { procedures) }\end{array}$ \\
\hline $\begin{array}{l}\text { Large migration out of } \\
\text { pore space }\end{array}$ & & & & & \\
\hline Caprock fracture & & & & & \\
\hline $\begin{array}{l}\text { Induced seismic event } \\
>\text { M4 }\end{array}$ & & & & & \\
\hline Massive release of CO2 \\
resulting in human \\
fatalities
\end{tabular}

Notes: Large migration out of pore space; caprock fracture; induced seismic event $\mathrm{m}>4$; massive release of $\mathrm{CO}_{2}$ resulting in human fatalities; catastrophic injection wellhead failure.

The pairwise preference matrix form of risk management options for pairs of LPHI indicate that for most scenarios, the group collectively identified definite preferences in 
ordering for risk management measures. The one scenario for which there is no clear consensus on effective measures is 'fatal massive $\mathrm{CO}_{2}$ release' (supplementary material). Supplementary material also provides:

1 bar charts showing mean of responses for effectiveness of risk management options for each LPHI, with the standard error of the mean score providing a measure of uncertainty in expert opinion

2 pairwise preference matrix form of risk management options for pairs of LPHI.

A large migration of $\mathrm{CO}_{2}$ out of the pore space could extend the plume to geological formations and anthropogenic features that were not assessed, thereby increasing the risk to performance and containment success. Jenkins et al. $(2015$, p.334) suggested that "the complex interplay of highly reflective thin layers, tuning effects, variable fluid saturation and mixing patterns, various modes of signal attenuation still renders full understanding of the plume highly challenging."

Caprock is the sealing formation of low permeability rock that is a critical feature for $\mathrm{CO}_{2}$ containment at a CCS site (IPCC, 2005). Its damage through caprock fracture, potentially caused by injection pressures, would open a pathway into or through the formation potentially enabling stored $\mathrm{CO}_{2}$ or brine to reach the surface environment.

Induced seismic events with magnitude $\mathrm{M}>4$, potentially caused by injection pressures, could result in unanticipated leakage scenarios through a fractured caprock or release through a fault pathway. In addition to potential $\mathrm{CO}_{2}$ or brine leakage that could affect drinking water, felt earthquake tremors are a concern with respect to public acceptance because of property damage or nuisance (White and Foxall, 2016). Birkholzer et al. (2015) linked slips on existing faults to broken seals. Both Pawar et al. (2015) and Celia et al. (2015) noted ongoing difficulty in risk assessment of induced seismicity, in part because of limited data sourced from large operations. White and Foxall (2016) reviewed technical difficulties associated with achieving effective risk assessment and risk management of induced seismicity, as well as progress to address them. Discussion included fault identification; microseismic event detection, location and characterisation; estimating earthquake recurrence and influence of injection; ground motion prediction; and structural and community vulnerability (White and Foxall, 2016).

A massive release of $\mathrm{CO}_{2}$ resulting in human fatalities could occur during capture, transport, injection, or storage activities, the latter through an existing wellbore. While normal air concentrations of $\mathrm{CO}_{2}$ are typically less than $1 \%$, the relatively large volume, concentrated and pressurised $\mathrm{CO}_{2}$ stream in CCS could pose a hazard to humans and other living organisms. The National Institute for Occupational Safety and Health defines an ambient $\mathrm{CO}_{2}$ concentration of $4 \%$ as immediately dangerous to life and health (IDLH) (Centers for Disease Control and Prevention, 2016), whereas the target purity of the supercritical $\mathrm{CO}_{2}$ stream is $97 \%-99.9 \%$ depending on the capture technology. Stream impurities, such as hydrogen sulphide, may also affect human health and the near surface biosphere (Koornneef et al., 2012).

Similarly, catastrophic injection wellhead failure could affect project workers, contaminate the local environment, reduce or shut down project performance and exacerbate public concern. Quintessa Ltd. (2018), the online $\mathrm{CO}_{2}$ database of features, events and processes, describes this event as an "uncontrolled flow of fluid (liquid, gas or supercritical fluid) into the injection wellbore, followed by [rapid] transport of the fluid to 
a shallower geological formation (underground blowout) or to the land surface or seabed."

\section{Discussion}

Environmental and human health risk management for CCS projects considers potential performance and containment hazards in an effort to ensure large scale integrated projects operate as planned. $\mathrm{CO}_{2}$ capture, transport, injection and geological storage need to be effectively and safely deployed by operators while operators and regulators need to minimise the likelihood and severity of local hazards and related risk issues. These include contamination of air, soil, or water resources from process contaminants, $\mathrm{CO}_{2}$, or brine; human, wildlife or livestock morbidity and mortality from exposure to highly concentrated $\mathrm{CO}_{2}$; and induced seismicity causing surface uplift or earthquake, with damage to infrastructure. The goal of permanently sequestering $\mathrm{CO}_{2}$ emissions and mitigating climate change, with associated benefits to the global environment and population health, could also be negated should there be higher than expected $\mathrm{CO}_{2}$ leakage rates.

A wide variety of risk management options should be considered and applied to an integrated, interdisciplinary technology such as CCS. As a principle of population health, coordinated action at multi-levels and multi-scales assists in protecting the determinants of health. While not comprehensive in terms of risk management options for CCS [also see Larkin et al. (2019b) in this issue], elicited target items are situated within five categories of action proposed by Krewski et al. (2007) and Krewski et al. (2014) under the REACT framework that considers regulatory, economic, advisory, community-based and technological options (Table 2). A number of options require action by stakeholders under more than one category of action.

Table 2 Elicited risk management options associated with five categories of action

\begin{tabular}{|c|c|c|c|}
\hline \multicolumn{4}{|c|}{ Risk management options } \\
\hline Regulatory & Advisory & Community-based & Technological \\
\hline \multicolumn{4}{|c|}{ Regulated leakage likelihood threshold } \\
\hline Regulated mandated cost allocation & Proponent' & cost commitment & \\
\hline Site selection & & Site selection & \\
\hline $\begin{array}{l}\text { Emergency response } \\
\text { plan }\end{array}$ & \multicolumn{2}{|c|}{ Emergency response plan } & \\
\hline $\begin{array}{l}\text { Automatic emergency } \\
\text { shut down }\end{array}$ & & & $\begin{array}{l}\text { Automatic } \\
\text { emergency shut } \\
\text { down }\end{array}$ \\
\hline \multirow[t]{3}{*}{ Well integrity studies } & $\begin{array}{l}\text { Well integrity } \\
\text { studies }\end{array}$ & & $\begin{array}{l}\text { Well integrity } \\
\text { studies }\end{array}$ \\
\hline & \multicolumn{3}{|c|}{ Training } \\
\hline & Monitoring & & \\
\hline
\end{tabular}




\subsection{Focus on environmental and human health protection}

Two primary concerns for CCS performance, containment and public perception risk management in injection and saline aquifer sequestration are $\mathrm{CO}_{2}$ or brine leakage (seepage) to the biosphere. For the shorter operations period, the group's performance-weighted median response suggests $88 \%$ of effort should be focused on human health compared with environmental protection (TQ56, Table 1). Experts also suggested greater health than environmental risk in capture compared with storage (Larkin et al., 2019a). As an economic risk management option, experts' central estimate was that $5.5 \%$ of injection and storage project costs should be mandated by regulatory agencies for both environment and human health protection, with a $90 \%$ credible range $\sim 1 \%-17 \%$ (TQ57, Table 1). Based on 2010 US\$ analysis of the FutureGen project's Environmental Impact Assessment, Trabucchi et al. (2012) suggested the damages to human health and the environment from pipeline ruptures and subsurface leakage could be less than $1 \%$ of total estimated project costs over a 100 -year operating period, but that the range in damage estimates would be site dependent.

Experts' numerical uncertainty distribution for the fraction of $\mathrm{CO}_{2}$ expected to be retained for the long-term (1,000 years) indicates the same median estimate judgement $(99.8 \%)$ for both saline aquifer and EOR projects (TQ46-47, Table 1). This is in keeping with the IPCC Special Report on Carbon Capture and Storage (IPCC, 2005), where a summary of evidence for retention and release rates suggested more than $99 \%$ of $\mathrm{CO}_{2}$ would be retained over the first 1,000 years. In 2005 and 2007, experts set the acceptable project leakage rate at $1 \%$ over 1,000 years for the Otway research project (Watson et al., 2014). Similarly, the containment risk target within a geosphere risk assessment workshop for the Weyburn-Midale EOR project was $99 \%$ retention of total injected mass of $\mathrm{CO}_{2}$ over 1,000 years (Bowden et al., 2013b). However, the expert panel's 90\% credible interval was greater for EOR, with the lower limit having greater variability than upper limit values (TQ46-47, Table 1). At the low/5th percentile, that is a 1 in 20 judged likelihood, experts' suggested $87 \%$ and $54 \%$ of $\mathrm{CO}_{2}$ would be retained in saline aquifer sequestration and the EOR project type over 1,000 years, respectively. Wilson et al. (2003) and IPCC (2005) suggested the effects of re-release are time-dependent, with less serious effects if anticipated leakage occurs in the long term. Nevertheless, re-release of unanticipated volumes of $\mathrm{CO}_{2}$, for reasons described by Meadowcroft and Langhelle (2009, p.284) as basic knowledge failure, practical knowledge failure, or significant regulatory failure, could affect the role of CCS in emissions reductions, thereby exacerbating public acceptance as well as anticipated population health benefits of climate change mitigation.

Responses to our set of elicitation questions on what should be the regulated threshold for the likelihood of minor, major, or catastrophic storage leakage suggested wide ranging views, possibly suggesting that this risk management strategy has not (yet) engaged the thinking of the expert panel in the way presented. A regulated threshold for leakage scenarios could be developed, as are used in risk management for industrial emissions of contaminants to air, soil and water. In their review, Koornneef et al. (2012) did not identify clear performance indicators (including amount of $\mathrm{CO}_{2}$ leaked) and recommended they be developed in conjunction with thresholds linked to potentially affected environmental compartments. Others have described a percentage of the total 
volume injected, for example $0.01 \%-0.001 \%$ per year ( $1 \%$ over 100 years up to $1 \%$ over 1,000 years) (IPCC, 2005; Stenhouse et al., 2009). In an attempt to assess the probability that leakage and leakage rate to atmosphere would surpass a regulated threshold, Gerstenberger et al. (2015) proposed an assessment structure to calculate rate, volume and concentration level of $\mathrm{CO}_{2}$ that would be compared to local health, safety, or environment standards.

Safety in the elicitation was defined as percentage of facilities not failing and the expert elicitation panel understood that a generic storage site would be properly selected, characterised and designed. The median response indicated that for greater than $95 \%$ of storage, these would remain safe for almost 13,000 years, albeit with wide $90 \%$ confidence bounds. Both the median number of years and uncertainty increased as the percent of safe facilities decreased (TQ43R-45R, Table 1). One expert indicated lifetimes one-to-two orders of magnitude longer than the rest of the group, extending the spreads of both performance weight and equal weight solutions in all three cases (supplementary material).

Markusson et al. (2012, p.912) suggested "there is uncertainty as to whether geological storage of $\mathrm{CO}_{2}$ will prove safe over long time periods, as well as if and how the associated risks can be reliably assessed and managed." In another application, safety criteria have been determined for Yucca Mountain, the potential geologic repository to store and dispose of high-level radioactive waste. The 2008 Environmental Protection Agency standard set a radiation dose limit to protect public health for the first 10,000 years after disposal, with a higher acceptable limit between 10,000 and 1 million years (US Environmental Protection Agency, 2016). Watson et al. (2014) also used the management of radioactive waste in the UK as an analogue case study regarding safe storage uncertainties that could inform CCS.

Given the long project lifespans, sometimes referred to as 'permanent sequestration' spanning centuries, Bachu (2008) discussed the assumption of long-term operational and financial liability for both monitoring and remediation in case of $\mathrm{CO}_{2}$ leakage. In addition to the injection and storage project costs should be mandated by regulatory agencies for both environment and human health protection, proponents could make a further financial commitment to be reasonably secure against gross negligence claims in any post-failure litigation. The experts' median estimate was approximately $11 \%$ of the injection and storage operational budget, double the suggested regulated amount. While the lower limit was equal for costs mandated and invested, the upper limit was more variable (TQ57-58, Table 1). Wilson et al. (2009) assessed the liability regime for CCS in the US and suggested risk management tools that could provide financial security to investors. While not limited to environmental or health impacts of leakage scenarios outside of normal operating conditions at CCUS projects, Pollak et al. (2013) proposed a leakage impact valuation (LIV) method to estimate the financial implications for wide ranging stakeholders (for both low and high cost storylines): leakage only, interference with each of subsurface activity and groundwater and migration to the surface. A cost category was included for legal expenses that may be incurred by the geological storage site operator to defend against lawsuits in the USA.

Should data be made available, further research into budgeting for existing and proposed CCS projects could begin to clarify and quantify proponents' perspectives and effort in environmental and human health risk management. 


\subsection{Low probability high impact events}

Dedicated risk management of LPHI is necessary for continued public and public sector support of this new technology. A poor outcome could not only affect containment risk, but public perception and public acceptance overall.

The elicitation considered risk management of LPHI events in two ways. Relative risk of four distinct causes of local health or environmental hazards was assessed using pairwise preference semi-quantitative ranking, as discussed in the companion article (Larkin et al., 2019a). In this question, experts ranked caprock integrity loss due to hydraulic fracturing as a lower relative hazard, but did not agree on the rank order of the other three hazards: brine, $\mathrm{HCO}_{3}$, or elevated gas-phase $\mathrm{CO}_{2}$ migration into the shallow subsurface and near-surface environment; a seismic event of magnitude $\mathrm{M} \geq 5$ on the Richter scale; or explosive re-release of $\mathrm{CO}_{2}$ to the surface.

These hazards were closely reiterated in the Likert-scale rating of risk management options for LPHI events (Table 3). Such hazards were also assessed as accidents, malfunctions and unintended events (AMUE) under the Canadian Environmental Assessment Act review of the Shell Quest project (Shell Canada Limited, 2010). Note that risk management in the present elicitation was focused on injection and storage and therefore excluded capture infrastructure included by Shell.

Table 3 Selection of low probability high impact (LPHI) events in carbon capture and storage

\begin{tabular}{|c|c|c|}
\hline $\begin{array}{l}\text { RM of five LPHI events } \\
\text { (Figure 3) }\end{array}$ & $\begin{array}{c}\text { Relative risk-distinct causes of } \\
\text { local environmental and human } \\
\text { health hazards (companion } \\
\text { article) }\end{array}$ & $\begin{array}{c}\text { Shell quest } \\
\text { Accidents, malfunctions and } \\
\text { unintended events } \\
\text { (Shell Canada Limited, 2010) }\end{array}$ \\
\hline $\begin{array}{l}\text { Large migration out of pore } \\
\text { space }\end{array}$ & $\begin{array}{c}\text { Brine/gas } \mathrm{CO}_{2} \text { migration into } \\
\text { shallow subsurface, near surface }\end{array}$ & \multirow{3}{*}{$\begin{array}{c}\text { Release of } \mathrm{CO}_{2}, \mathrm{BCS} \text { brine or } \\
\mathrm{CO}_{2} \text { saturated brine from the } \\
\text { storage complex or injection } \\
\text { wells }\end{array}$} \\
\hline $\begin{array}{l}\text { Induced seismic } M>4 \\
\text { quake }^{1}\end{array}$ & Seismic event $M>5^{1}$ & \\
\hline Caprock fracture & $\begin{array}{c}\text { Caprock integrity loss due to } \\
\text { hydraulic fracturing }\end{array}$ & \\
\hline $\begin{array}{l}\text { Massive release of } \mathrm{CO}_{2} \\
\text { resulting in human fatalities }\end{array}$ & $\begin{array}{c}\text { Explosive re-release of } \mathrm{CO}_{2} \text { to } \\
\text { the surface }\end{array}$ & $\begin{array}{l}\mathrm{CO}_{2} \text { pipeline rupture or } \\
\text { injection well head failure }\end{array}$ \\
\hline \multicolumn{3}{|l|}{$\begin{array}{l}\text { Catastrophic wellhead } \\
\text { failure }\end{array}$} \\
\hline & & $\begin{array}{c}\text { Process upsets in } \mathrm{CO}_{2} \text { capture } \\
\text { infrastructure }\end{array}$ \\
\hline
\end{tabular}

Note: ${ }^{1}$ Slightly different cut-off in each question.

An interesting finding of the elicitation is the dichotomy of risk management approaches deemed effective for three LPHI leakage georisks compared with events more directly related to human health and safety (Figure 3). Only site selection and monitoring were considered 'very' effective risk management options for large migration out of pore space, caprock fracture and induced seismic event $M>4$. However, with the exception of site selection, the other five risk management options - well integrity studies, emergency response plan, monitoring, automatic emergency shut down system and training - were considered 'very' or 'extremely' effective in managing the potential massive release of $\mathrm{CO}_{2}$ and catastrophic wellhead failure. The expert panel collectively identified order 
preferences for most risk management options for most scenarios (supplementary material). The one scenario for which there was no clear consensus on effective measures is 'massive release of $\mathrm{CO}_{2}$ resulting in human fatalities', where the heat matrix indicates high effectiveness for all options except site selection.

Wilson et al. (2008) discussed the special attention that could apply to injection in CCS sequestration projects, given projected high volumes and inherent buoyancy in the supercritical state. Both individual and societal risk estimates could be calculated. In the Weyburn-Midale EOR project geosphere risk assessment, it was assumed that the public safety (societal) risk would be unacceptable if it exceeded a probability of $1 \times 10^{-3}$ per year of one or more fatalities (the Australian National Committee tolerability for Large Dams (ANCOLD) guideline limit); and that it would be marginally acceptable if it was between this tolerability limit and a lesser probability level of $1 \times 10^{-4}$ per year (Bowden et al., 2013b). Pawar et al. (2015) found that one sequestration project application, FutureGen in the USA, estimated the frequency of an eruptive event to be remote (probability of $<10^{-6}$ per 5,000 years). Jenkins et al. (2015) found that analyses have not assessed significant adverse effects on the environment or other resources very well and that contingency planning for an adverse event has not been well developed.

Indeed, Larkin et al. (2019b), identified few RA/RM frameworks in the regulatory context that include a requirement for contingency plans for large incidents, being limited to the United Nations Framework Convention on Climate Change (2011) modalities and procedures for CCS as a clean development mechanism, Australia's Offshore Petroleum and Greenhouse Gas (Environment) Regulation (Australian Government, 2014) and the US State of Kansas enabling legislation (Kansas State Corporation Commission, 2010). As a non-regulatory guidance document, DNV $\mathrm{CO}_{2}$ RiskMan (2013) provides extensive hazard risk management guidance to consider the large quantity, concentrated and pressurised nature of the $\mathrm{CO}_{2}$ stream within the capture, transport and injection chain activities (Det Norske Veritas, 2013; Holt et al., 2012). However, impacts to groundwater quality from $\mathrm{CO}_{2}$ or brine, as well as the storage chain, are excluded from the guidance document. Pawar et al. (2015) concluded that research has reduced uncertainty for some major risk issues, such as leakage pathways and induced seismicity, but that more limited efforts have been made to quantify other low probability events of high consequence such as well blowout or catastrophic caprock failure.

An area of further research could consider why site selection was not judged more effective to manage human health risks considering that this phase in project development could underpin safety overall. It is possible the expert panel considered proper site selection having already been completed and so site selection could do nothing more to limit LPHI events.

\subsection{Emphasis on monitoring}

Monitoring options for CCS help to manage performance, containment and public perception risk issues in leakage and safety. In considering a suitable monitoring period, the experts' median estimate is 92 years, i.e., about a century in duration (TQ55, Table 1). However, responses included uncertainty of three orders of magnitude, with a credible upper limit of almost 1,000-year monitoring period. A monitoring plan during the operations phase of CCS sequestration projects is a mandatory or voluntary activity in a wide variety of elaborated risk assessment and risk management frameworks developed in the regulatory and non-regulatory context (Larkin et al., 2019b). 
Dixon et al. (2015) noted that monitoring is based on site specific risk assessments and that review articles to share good practice and learnings are forthcoming. One of the most detailed existing documents is the US National Energy Technology Laboratory (2017) guidance on monitoring, verification and accounting of $\mathrm{CO}_{2}$ stored in deep geologic formations. (This general topic is usually referred to as MMV - monitoring, measurement and verification - but in the USA it is also called MVA - monitoring, verification and accounting). In 2012, the NETL best practices was that projects demonstrate $99 \%$ retention of $\mathrm{CO}_{2}$ through GS [geological sequestration], up from $95 \%$ in 2008. These retention levels were defined by the ability of a sequestration site to detect $\mathrm{CO}_{2}$ leakage at levels of $5 \%$ and $1 \%$ of the stored amount of $\mathrm{CO}_{2}$ into the atmosphere. Jenkins et al. (2015) reviewed advances in monitoring technologies. In Alberta, the Quantification Protocol for $\mathrm{CO}_{2}$ Capture and Permanent Storage in Deep Saline Aquifers (Government of Alberta, 2015) requires MMV of containment, as described in the Alberta Energy Regulator directives for MMV activities under the Mines and Minerals Act. Project developers must attempt "to ensure there are no emissions from the subsurface to the atmosphere" (Government of Alberta, 2015, p.56). Bourne et al. (2014) describe the MMV plan for the quest project operating in that province.

Project leaders and regulators continuously improve understanding of injectivity and storage parameters such as flow and pressures, ultimately seeking to demonstrate that a storage site is operating safely and reliably as planned. With respect to LPHI, Jenkins et al. (2015, p.343) suggested that "explicit consideration of significant adverse events would be helpful in designing monitoring strategies and clarifying requirements." This review acknowledged the need for a number of techniques, also suggesting monitoring could nevertheless miss significant adverse events, notwithstanding the evidence from the past decade that has demonstrated these risks to be small and indeed less than risks posed by climate change.

With the emphasis on monitoring as one of the preferred RM options, effective mitigation responses are also required should an adverse circumstance be identified. Guénan et al. (2011) created a database of mitigation measures for risk events and Manceau et al. (2014) provide a review of mitigation and remediation technologies and practices for the case of undesired $\mathrm{CO}_{2}$ migration in a storage unit. Farhat and Benson (2015) proposed a methodological framework that aims to link risk assessment to corrective measures, using a collaborative and transparent contingency planning process; this could have potential application to LPHI events. On the other hand, Pawar et al. (2015) suggested that an assessment of mitigation options themselves is not well advanced.

\section{Conclusions}

In an effort to assess and address potential hazards associated with an activity or innovation, risk assessment and management has been undertaken conjointly and are fundamentally matters of judgement in probability and uncertainty (National Research Council, 1983). Within this context, efforts attempt to determine acceptable societal risk and risk control options.

In this paper, findings from a structured expert elicitation provide insights into target questions focused on CCS issues in risk management. A companion article provides the expert panel's judgements on a series of risk assessment target questions that provide a 
backdrop to the risk management options discussed here (Larkin et al., 2019a). Findings include pairwise rankings of risks between technology, environment and health in each domain of capture, transport, injection and storage; experts' best estimate and uncertainty bounds for likelihood of leakage in each of capture, transport, injection and storage (the latter over three time periods); judgements for the likelihood and severity of well leakage, injection, intrinsic storage and induced storage hazards that could cause leakage or seepage; and judgements on the likelihoods of major $\mathrm{CO}_{2}$ storage leakage that would require an intervention to mitigate negative environmental impacts or adverse public health impacts over three time periods: $0-50$ years, $51-499$ years and $500+$ years. This article also provides comments on the elicitation process.

In conjunction with findings for risk assessment, we have increased understandings of relative risk and quantified collective uncertainty judgements for a variety of difficult decision challenges for CCS. Some responses to quantitative target questions conveyed larger judged uncertainties than others. For example, the percentage of facilities achieving safe storage lifetimes as a function of time ranged over five orders of magnitude. In almost all cases the performance weight uncertainty was less than equal weight. CCS is a multidisciplinary approach to climate change mitigation requiring a diversity of expertise for safe and secure $\mathrm{CO}_{2}$ injection and sequestration in the long term. It is hoped that outcomes reported here might stimulate further scientific deliberations towards achieving objective judgements on CCS risk issues.

Risk management of low probability high impact (LPHI) events is particularly important because effects could unfold at both the local and global scales, both within the project's designated area of influence or emergency planning zone and more broadly with respect to public acceptability of the CCS technology worldwide. A LPHI event has the potential to seriously affect the future implementation of $\mathrm{CCS}$ - whether a major accident resulting in morbidity or mortality, unintended large migration of $\mathrm{CO}_{2}$ out of the pore space, caprock fracture, or an induced significant seismic event. Site selection and monitoring were deemed very effective georisk management options; and five options of well integrity studies, emergency response plan, monitoring, automatic emergency shut down system and training considered 'very' or 'extremely' effective in managing the potential massive release of $\mathrm{CO}_{2}$ resulting in human fatalities or catastrophic wellhead failure.

The emphasis on monitoring as a risk management option leads to the question of how long this should continue and potential mitigation of an adverse event. Our experts' pooled median response was a period of almost 100 years, although reservations, arising from uncertainty, could plausibly extend this to almost 1,000 years. The development of robust protocols for credible monitoring and verification and the testing of these protocols in public engagement processes, could be viewed as essential for risk acceptability of CCS. Public understanding for the proposed response(s) to an adverse measurement is likely of equal importance.

The findings and insights from the expert elicitation of scientific judgements reported here illustrate risk management options that could be considered during the review and approval of potentially thousands of deep geological saline aquifer sequestration projects worldwide. Indeed, public stakeholders could be unforgiving if hazard assessment and risk management in CCS is considered insufficient, thus affecting future implementation of this climate change mitigation technology. On the other hand, comprehensive risk assessments and rational risk management could impact public perception for CCS positively, in turn instilling confidence, public acceptance and ongoing support. 
Supplementary material is available online at Harvard Dataverse (https://dataverse.harvard.edu/)

\section{Acknowledgements}

The authors are most grateful to the experts who participated in the elicitation (the order here not reflected in the anonymised range graphs): Stefan Bachu, Michael Celia, Rick Chalaturnyk, Jean-Pierre Deflandre, William Gunter, Don Lawton, Curtis Oldenburg, Lincoln Paterson, David Ryan, J. Carlos Santamarina and Ton Wildenborg. The authors also thank three anonymous reviewers. This work was supported by DK, the Natural Sciences and Engineering Research Council of Canada Chair in Risk Science at the University of Ottawa. WPA was supported in part by the UK Natural Environment Research Council CREDIBLE consortium (Grant NE/J017299/1).

\section{References}

Aspinall, W. (2010) 'A route to more tractable expert advice', Nature, 21 January, Vol. 463, pp.294-295.

Aspinall, W.P. and Cooke, R.M. (2013) 'Expert elicitation and judgement', in Rougier, J.C., Sparks, R.S.J. and Hill, L. (Eds.): Risk and Uncertainty Assessment in Natural Hazards, pp.64-99, Cambridge University Press, Cambridge, UK.

Australian Government (2014) Offshore Petroleum and Greenhouse Gas Storage (Environment) Regulations, 2009 [online] https://www.comlaw.gov.au/Details/F2014C00210 (accessed 23 August 2018).

Bachu, S. (2008) ' $\mathrm{CO}_{2}$ storage in geological media: role, means, status and barriers to deployment', Progress in Energy and Combustion Science, Vol. 34, No. 2, pp.254-273.

Birkholzer, J.T., Oldenburg, C.M. and Zhou, Q. (2015) ' $\mathrm{CO}_{2}$ migration and pressure evolution in deep saline aquifers', International Journal of Greenhouse Gas Control, Vol. 40, pp.203-220, DOI: $10.1016 /$ j.ijggc.2015.03.022.

Bourne, S., Crouch, S. and Smith, M. (2014) 'A risk-based framework for measurement, monitoring and verification of the Quest CCS Project, Alberta, Canada', International Journal of Greenhouse Gas Control, Vol. 26, pp.109-126, DOI: 10.1016/j.ijggc.2014.04.026.

Bowden, A.R., Pershke, D.F. and Chalaturnyk, R. (2013a) 'Biosphere risk assessment for $\mathrm{CO}_{2}$ storage projects', International Journal of Greenhouse Gas Control, Vol. 16, pp.S291-S308, DOI: 10.1016/j.ijggc.2013.02.015.

Bowden, A.R., Pershke, D.F. and Chalaturnyk, R. (2013b) 'Geosphere risk assessment conducted for the IEAGHG Weyburn-Midale $\mathrm{CO}_{2}$ monitoring and storage project', International Journal of Greenhouse Gas Control, Vol. 16, pp.S276-S290, DOI: 10.1016/j.ijggc.2013.02.014.

Celia, M.A., Bachu, S., Nordbotten, J.M. and Bandilla, K.W. (2015) 'Status of $\mathrm{CO}_{2}$ storage in deep saline aquifers with emphasis on modeling approaches and practical simulations', Water Resources Research, Vol. 51, p.47, DOI: 10.1002/2015WR017609.

Centers for Disease Control and Prevention (2016) The National Institute for Occupational Safety and Health (NIOSH) [online] http://www.cdc.gov/niosh/idlh/124389.html (accessed 6 September 2018).

Cooke, R.M. (1991) Experts in Uncertainty: Opinion and Subjective Probability in Science, Oxford University Press, New York, NY. 
Cooke, R.M. (2013) 'Validating expert judgment with the classical model', in Martini, C. and Boumans, M. (Eds.): Ethical Economy: Studies in Economic Ethics and Philosophy [online] http://www.expertsinuncertainty.net/LinkClick.aspx?fileticket=HlcTmEoDunY\%3D\&tabid=4 $385 \& \mathrm{mid}=8296$ (accessed 23 August 2018).

Cooke, R.M. and Goossens, L.L.H.J. (2008) 'TU delft expert judgment database', Reliability Engineering and Systems Safety, Vol. 93, pp.657-674, DOI: 10.1016/j.ress.2007.03.005.

Damen, K., Faaij, A. and Turkenburg, W. (2006) 'Health, safety and environmental risks of underground $\mathrm{CO}_{2}$ storage - overview of mechanisms and current knowledge', Climatic Change, Vol. 74, Nos. 1-3, pp.289-318.

Det Norske Veritas (2013) $\mathrm{CO}_{2} \mathrm{RISKMAN}$, Guidance on $\mathrm{CCS} \mathrm{CO}_{2}$ Safety and Environment, Major Accident Hazard Risk Management, Level 1, 2, 3 and 4 [online] https://www.dnvgl.com/ oilgas/joint-industry-projects/ongoing-jips/co2riskman.html (accessed 6 September 2018).

Dixon, T., McCoy, S.T. and Havercroft, I. (2015) 'Legal and regulatory developments on CCS', International Journal of Greenhouse Gas Control, Vol. 40, pp.431-448, DOI: 10.1016/j.ijggc.2015.05.024.

Farhat, K. and Benson, S.M. (2015) Translating Risk Assessment to Contingency Planning for $\mathrm{CO}_{2}$ Geologic Storage: A Methodological Framework [online] https://www-cdn.law.stanford.edu/ wp-content/uploads/2016/02/CCS_Contingency_V20FV3SB_V4_FinalF.pdf (accessed 31 August 2016).

GCCSI (2014) The Global Status of CCS: 2014 [online] http://decarboni.se/sites/default/files/ publications/180923/global-status-ccs-2014.pdf (accessed 16 August 2018).

GCCSI (2016) Large-scale CCS Projects - Definitions [online] http://www.globalccsinstitute.com/ projects/large-scale-ccs-projects-definitions (accessed 6 September 2018).

Gerstenberger, M.C. and Christophersen, A. (2016) 'A Bayesian network and structured expert elicitation for Otway Stage 2C: detection of injected $\mathrm{CO}_{2}$ in a saline aquifer', International Journal of Greenhouse Gas Control, Vol. 51, pp.317-329, DOI: 10.1016/j.ijggc.2016.05.011.

Gerstenberger, M.C., Christophersen, A., Buxton, R. and Nicol, A. (2015) 'Bi-directional risk assessment in carbon capture and storage with Bayesian networks', International Journal of Greenhouse Gas Control, Vol. 35, pp.150-159, DOI: 10.1016/j.ijggc.2015.01.010.

Gerstenberger, M.C., Christophersen, A., Buxton, R., Allinson, G., Hou, W., Leamon, G. and Nicol, A. (2013) 'Integrated risk assessment for CCS', Energy Procedia, Vol. 37, pp.2775-2782, DOI: 10.1016/j.egypro.2013.06.162.

Government of Alberta (2015) Quantification Protocol for $\mathrm{CO}_{2}$ Capture and Permanent Storage in Deep Saline Aquifers [online] https://open.alberta.ca/publications/9780778572213 (accessed 23 August 2018).

Guénan, T.L., Manceau, J-C., Bouc, O., Rohmer, J. and Ledoux, A. (2011) 'GERICO: a database for $\mathrm{CO}_{2}$ geological storage risk management', Energy Procedia, Vol. 4, pp.4124-4131, DOI:. 10.1016/j.egypro.2011.02.356.

Holt, H., Helle, K. and Brown, J. (2012) ' $\mathrm{CCS} \mathrm{CO}_{2}$ risk management - new industry guidance', 23rd Institution of Chemical Engineers Symposium on Hazards 2012158 Ed [online] http://www.scopus.com/inward/record.url?eid=2-s2.0-84888426233\&partnerID=40\&md5= 076b2fbcaba332922d5a6a7fcb1107dd (accessed 31 August 2018).

International Energy Agency (IEA) (2009) Technology Roadmap: Carbon Capture and Storage [online] https://www.iea.org/publications/freepublications/publication/CCSRoadmap2009.pdf (accessed 10 October 2018).

International Energy Agency (IEA) (2013) Technology Roadmap Carbon Capture and Storage [online] https://www.iea.org/publications/freepublications/publication/ TechnologyRoadmapCarbonCaptureandStorage.pdf (accessed 16 August 2018).

IPCC (2005) IPCC Special Report on Carbon Dioxide Capture and Storage [online] http://www.ipcc.ch/pdf/special-reports/srccs/srccs_wholereport.pdf (accessed 16 August 2018). 
IPCC (2014) Summary for Policy Makers, Mitigation of Climate Change [online] http://www.ipcc.ch/report/ar5/wg3/ (accessed 16 August 2018).

Jenkins, C., Chadwick, A. and Hovorka, S.D. (2015) 'The state of the art in monitoring and verification - ten years on', International Journal of Greenhouse Gas Control, Vol. 40, pp.312-349, DOI: 10.1016/j.ijggc.2015.05.009.

Jones, D.G., Beaubien, S.E., Blackford, J.C., Foekema, E.M., Lions, J., De Vittor, C., West, J.M., Widdicombe, S., Hauton, C. and Queirós, A.M. (2015) 'Developments since 2005 in understanding potential environmental impacts of $\mathrm{CO}_{2}$ leakage from geological storage', International Journal of Greenhouse Gas Control, Vol. 40, pp.350-377, DOI: 10.1016/j.ijggc.2015.05.032.

Kansas State Corporation Commission (2010) Permanent Administrative Regulations Article 3 Production and Conservation of Oil and Gas [online] http://www.kssos.org/pubs/ register\%5C2010\%5CVol_29_No_06_February_11_2010_p_165-196.pdf (accessed 23 August 2018)

Koornneef, J., Ramirez, A., Turkenburg, W. and Faaij, A. (2012) 'The environmental impact and risk assessment of $\mathrm{CO}_{2}$ capture, transport and storage - an evaluation of the knowledge base', Progress in Energy and Combustion Science, Vol. 38, pp.62-86, DOI: 10.1016/j.pecs.2011.05.002.

Krewski, D., Hogan, V., Turner, M.C., Zeman, P.L., McDowell, I., Edwards, N. and Losos, J. (2007) 'An integrated framework for risk management and population health', Human and Ecological Risk Assessment: An International Journal, Vol. 13, No. 6, pp.1288-1312, DOI: 10.1080/10807030701655798.

Krewski, D., Westphal, M., Andersen, M.E., Paoli, G.M., Chiu, W.A., Al-Zoughool, M., Croteau, M.C., Burgoon, L.D. and Cote, I. (2014) 'A framework for the next generation of risk science', Environ Health Perspect, Vol. 122, No. 8, pp.796-805, DOI: 10.1289/ehp.1307260.

Larkin, P., Dusseault, M., Gracie, R.G., Sarkarfarshi, A.M., Shafiei, A., Aspinall, W. and Krewski, D. (2019a) 'Uncertainty in risk issues for carbon capture and storage: findings from a structured expert elicitation', International Journal of Risk Assessment and Management, in this issue.

Larkin, P., Leiss, W., Arvai, J., Gracie, R.G., Fall, M., Dusseault, M.D., Heyes, A. and Krewski, D. (2019b) 'An integrated risk management framework for carbon capture and storage: a Canadian perspective', International Journal of Risk Assessment and Management, in this issue.

Larkin, P., Leiss, W. and Krewski, D. (2019c) 'Risk assessment and management frameworks for carbon capture and storage: a global perspective', International Journal of Risk Assessment and Management, in this issue.

Macutkiewicz, M. and Cooke, R.M. (2006) UNIBALANCE Users Manual [online] http://dutiosc.twi.tudelft.nl/ risk/images/stories/UnibalancePage/Unibalance_User_Manual.pd f (accessed 4 August 2018)

Manceau, J.C., Hatzignatiou, D.G., de Lary, L., Jensen, N.B. and Réveillère, A. (2014) 'Mitigation and remediation technologies and practices in case of undesired migration of $\mathrm{CO}_{2}$ from a geological storage unit - current status', International Journal of Greenhouse Gas Control, Vol. 22, pp.272-290, DOI: 10.1016/j.ijggc.2014.01.007.

Markusson, N., Kern, F., Watson, J., Arapostathis, S., Chalmers, H., Ghaleigh, N., Heptonstall, P., Pearson, P., Rossati, D. and Russell, S. (2012) 'A socio-technical framework for assessing the viability of carbon capture and storage technology', Technological Forecasting and Social Change, Vol. 79, No. 5, pp.903-918, DOI: 10.1016/j.techfore.2011.12.001.

Meadowcroft, J. and Langhelle, O. (Eds.) (2009) Caching the Carbon: The Politics and Policy of Carbon Capture and Storage, Edward Elgar, Cheltenham, UK.

MIT (2018) Carbon Capture \& Sequestration Project Database [online] http://sequestration.mit. edu/tools/projects/index.html (accessed 19 August 2018). 
National Energy Technology Laboratory (2017) Best Practices: Monitoring, Verification, and Accounting (MVA) of Geologic Storage Projects [online] https://www.netl.doe.gov/ File\%20Library/Research/Carbon-Storage/Project-Portfolio/BPM-MVA-2012.pdf (accessed 7 September 2018).

National Research Council (1983) Risk Assessment in the Federal Government: Managing the Process [online] www.nap.edu/catalog/366.html (accessed 16 August 2018).

Oraby, T., Tyshenko, M., Westphal, M., Darshan, S., Croteau, M., Aspinall, W., Elsaadany, S., Cashman, N. and Krewski, D. (2016) 'Using expert judgments to improve chronic wasting disease management in Canada', Journal of Toxicology and Environmental Health, Vol. 79, Nos. 16-17, pp.713-28, DOI: 10.1080/15287394.2016.1174005.

Pawar, R., Bromhal, G., Carroll, S., Chu, S., Dilmore, R., Gastelum, J., Oldenburg, C., Stauffer, P., Zhang, Y. and Guthrie, G. (2014) 'Quantification of key long-term risks at $\mathrm{CO}_{2}$ sequestration sites: latest results from US DOE's National Risk Assessment Partnership (NRAP) project', Energy Procedia, Vol. 63, pp.4816-4823, DOI: 10.1016/j.egypro.2014.11.512.

Pawar, R.J., Bromhal, G.S., Carey, J.W., Foxall, W., Korre, A., Ringrose, P.S., Tucker, O., Watson, M.N. and White, J.A. (2015) 'Recent advances in risk assessment and risk management of geologic $\mathrm{CO}_{2}$ storage', International Journal of Greenhouse Gas Control, Vol. 40, pp.292-311, DOI: 10.1016/j.ijggc.2015.06.014.

Pollak, M.F., Bielicki, J.M., Dammel, J.A., Wilson, E.J., Fitts, J.P. and Peters, C.A. (2013) 'The leakage impact valuation (LIV) method for leakage from geologic $\mathrm{CO}_{2}$ storage reservoirs', Energy Procedia, Vol. 37, pp.2819-2827, DOI: 10.1016/j.egypro.2013.06.167.

Quintessa Ltd. (2018) $\mathrm{CO}_{2}$ FEP Database [online] https://www.quintessa.org/co2fepdb/v2.0.0/PHP/ frames.php (accessed 16 August 2018).

Shell Canada Limited (2010) Quest Carbon Capture and Storage Project Environmental Assessment, Section 17: Accidents, Malfunctions and Unplanned Events, available through Alberta Energy Regulator CD of documents related to the Quest application.

Stenhouse, M.J., Gale, J. and Zhou, W. (2009) 'Current status of risk assessment and regulatory frameworks for geological $\mathrm{CO}_{2}$ storage', Energy Procedia, Vol. 1, No. 1, pp.2455-2462, DOI: 10.1016/j.egypro.2009.02.007.

Trabucchi, C., Donlan, M., Huguenin, M., Konopka, M. and Bolthrunis, S. (2012) Valuation of Human Health and Ecological Risks Arising from Carbon Capture and Storage (CCS): Final Study Observations, no longer available online, (accessed 14 July 2016).

Tyshenko, M., Elsaadany, S., Oraby, T., Darshan, S., Catford, A., Aspinall, W., Cooke, R. and Krewski, D. (2012) 'Expert judgement and re-elicitation for prion disease risk uncertainties', International Journal of Risk Assessment and Management, Vol. 16, No. 1/2/3, pp.48-77.

Tyshenko, M.G., ElSaadany, S., Oraby, T., Darshan, S., Aspinall, W., Cooke, R., Catford, A. and Krewski, D. (2011) 'Expert elicitation for the judgment of prion disease risk uncertainties', J Toxicol Environ Health A, Vol. 74, Nos. 2-4, pp.261-85, DOI: $10.1080 / 15287394.2011 .529783$.

United Nations Framework Convention on Climate Change (2011) Modalities and Procedures for Carbon Dioxide Capture and Storage in Geological Formations as Clean Development Mechanism Project Activities [online] http://unfccc.int/resource/docs/2011/cmp7/eng/ 10a02.pdf\#page=13 (accessed 23 August 2018).

US Environmental Protection Agency (2016) Public Health and Environmental Radiation Protection Standards for Yucca Mountain, Nevada (40 CFR Part 197) [online] https://www.epa.gov/radiation/public-health-and-environmental-radiation-protectionstandards-yucca-mountain-nevada-40 (accessed 22 June 2018).

Watson, J., Kern, F. and Markusson, N. (2014) 'Resolving or managing uncertainties for carbon capture and storage: lessons from historical analogues', Technological Forecasting and Social Change, Vol. 81, pp.192-204, DOI: 10.1016/j.techfore.2013.04.016.

White, J.A. and Foxall, W. (2016) 'Assessing induced seismicity risk at $\mathrm{CO}_{2}$ storage projects: recent progress and remaining challenges', International Journal of Greenhouse Gas Control, Vol. 49, pp.413-424, DOI: 10.1016/j.ijggc.2016.03.021. 
Wilson, E.J., Johnson, T.L. and Keith, D.W. (2003) 'Regulating the ultimate sink: managing the risks of geologic $\mathrm{CO}_{2}$ storage', Environmental Science and Technology, Vol. 37, No. 16, pp.3476-3483, DOI: 10.1021 /es021038.

Wilson, E.J., Klass, A.B. and Bergan, S. (2009) 'Assessing a liability regime for carbon capture and storage', Energy Procedia, Vol. 1, No. 1, pp.4575-4582, DOI: 10.1016/j.egypro.2009.02.277.

Wilson, E.J., Morgan, M.G., Apt, J., Bonner, M., Bunting, C., Gode, J., Haszeldine, R.S., Jaeger, C.C., Keith, D.W., McCoy, S.T., Pollak, M.F., Reiner, D.M., Rubin, E.S., Torvanger, A., Ulardic, C., Vajjhala, S.P., Victor, D.G. and Wright, I.W. (2008) 'Regulating the geological sequestration of $\mathrm{CO}_{2}$ ', Environmental Science and Technology, Vol. 42, No. 8, pp.2718-2722. 